
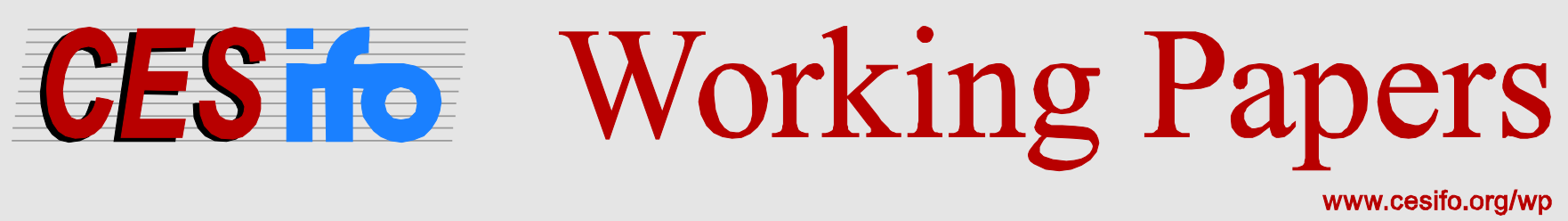

\title{
Will Skyscrapers Save the Planet? Building Height Limits and Urban Greenhouse Gas Emissions
}

\author{
Rainald Borck
}

\author{
CESIFO WORKING PAPER No. 4773 \\ CATEGORY 10: ENERGY AND ClimATE ECONOMICS \\ APRIL 2014
}

An electronic version of the paper may be downloaded

- from the SSRN website:

- from the RePEc website:

- from the CESifo website:

WwW.SSRN.com

www.RePEc.org

www.CESifo-group.org/wp

\section{CESifo}




\title{
Will Skyscrapers Save the Planet? Building Height Limits and Urban Greenhouse Gas Emissions
}

\begin{abstract}
This paper studies the effectiveness of building height limits as a policy to limit greenhouse gas (GHG) emissions. It shows that building height limits lead to urban sprawl and higher emissions from commuting. On the other hand, aggregate housing consumption may decrease which reduces emissions from residential energy use. A numerical model is used to show that total GHG emissions may be lower under building height restrictions, but only when they are very strict. Welfare is not concave in the strictness of building height limits, so either no limit or a very strict one might maximize welfare. The paper also studies the effect of endogenous transport technology and the urban heat island effect.
\end{abstract}

JEL-Code: Q500, R100.

Keywords: greenhouse gas emissions, city structure, building height limits.

\author{
Rainald Borck \\ Department of Economics \\ University of Potsdam \\ August-Bebel-Str. 89 \\ Germany - 14482 Potsdam \\ rainald.borck@uni-potsdam.de
}

April 16, 2014

I would like to thank Jan Brueckner, Kristof Dascher and Tatsuhito Kono for helpful comments and Marie Bessec for kind provision of data. 


\section{Introduction}

Can skyscrapers save the planet? Are densely populated cities with high-rise buildings good or bad for the environment? This paper sets out to analyze this question in an urban land use model with commuting and housing as sources of greenhouse gas (GHG) emissions.

Some analysts and commentators are afraid of the environmental consequences of urbanisation. For instance, Seto et al. (2012) argue that the projected urbanization until 2030 leads to significant loss of biodiversity and increased $\mathrm{CO}_{2}$ emissions due to deforestation and land use changes. Intuitively, cities use up land which cannot be used for forests and other green vegetation areas, with concomitant negative effects for the environment.

On the other hand, there are also those who claim that densely populated cities produce lower per capita emissions. For instance, Glaeser and Kahn (2010) show that in the US, inhabitants of densely populated cities such as New York City and San Francisco tend to produce lower $\mathrm{CO}_{2}$ emissions from transport and residential energy use than those living in less densely populated cities such as Houston, controlling for factors such as local weather. This line of reasoning has prompted organizations such as the OECD and the World Bank to advocate high density urban development to mitigate environmental pollution. In this spirit, Glaeser (2009) writes: "To save the planet, build more skyscrapers".

This paper analyzes whether limiting building heights is good or bad for the environment. So why would dense high-rise buildings be good for the environment? There are two main effects to consider. First, when buildings are tall and population density is high, households tend to live close to their work, which reduces the need to commute. Since commuting is one of the largest drivers of GHG emissions, artificially limiting population density by reducing building heights would tend to increase GHG emissions (Glaeser and Kahn, 2010). The second effect is on housing. Intuitively, one might think that the effect is similar. When population is large, land is scarce, developers build high-rise buildings and dwellings are small. However, limiting building heights restricts the supply of housing, which drives up housing prices and leads to smaller dwellings. I show that GHG emissions from residential electricity and energy use may fall as a result of building height restrictions.

The economic literature on urban structure and the environment is relatively small. Glaeser and Kahn (2010) use US data to study GHG emissions by residents of different cities. The focus of the study is on emissions from urban transport and residential energy use, and how these are shaped by urban structure, such as the density of housing 
development.

Gaigné et al. (2012) study environmental externalities in a new economic geography framework, pointing to the importance of the urban system as well as the structure of single cities. They analyze emissions from commuting and goods transport. Borck and Pflüger (2013) extend this framework to include emissions from industrial and agricultural production and housing. Legras and Cavailhès (2012) introduce land use as a source of GHG emissions into the same kind of model. Larson et al. (2012) use an urban model similar to the present one and study how energy use from commuting and housing changes with various policies, including building height restrictions. They find that such restrictions increase total emissions with the parameters they use for their quantitative model. This paper uses a standard urban model and studies building height restrictions as introduced by Bertaud and Brueckner (2005). In contrast to Larson et al. (2012), I analyze under what conditions building height restrictions are harmful or not for the environment. In fact, I find that for certain constellations, such restrictions may be good for the environment. The stricter the restriction on building height, the more likely it is that total energy use from residential housing decreases and hence total emissions fall. Dascher (2013) also analyzes the effect on urban structure on the environment. However, he focuses on how the exogenous 'city silhouette' affects residents' desire to increase carbon taxes. Also, he does not explicitly consider the equilibrium urban structure, nor are there externalities in his model. ${ }^{1}$

There are also a few papers that study building height restrictions as second-best policies in the presence of externalities. For instance, Joshi and Kono (2009) study FAR limits in an urban model with population growth to address externalities. Kono et al. (2012) use a similar setup to study FAR limits as a second-best tool to mitigate traffic congestion. Neither paper, however, considers environmental externalities or, more particularly GHG emissions. Also, the current paper more explicitly looks at emissions from commuting and residential energy use in cities with different climates.

The paper proceeds as follows. The next section presents the model. Section 3 simulates the model numerically to gauge whether building height restrictions can reduce pollution using realistic parameters. In Section 4, I present two extensions: first, urban heat islands that is, the fact that cities are hotter than rural areas and this effect may depend on urban structure - and transport mode choice, which affects the emissions from urban commuting. Section 5 introduces pollution externalities into the utility function. This allows me to

\footnotetext{
${ }^{1}$ See also Tscharaktschiew and Hirte (2010) on the effects of carbon taxes in an urban economic model.
} 
study the welfare effects from building height restrictions, which weigh the cost in terms of a distorted housing market against the possible benefit of reduced pollution. Section 6 conducts some sensitivity analysis by varying key parameters of the model. The last section concludes the paper.

\section{The model}

The model introduces environmental pollution into a standard monocentric city model with building height restrictions (Bertaud and Brueckner, 2005). Consider a closed circular city with a fixed number $N$ of residents. Each household has a strictly increasing and quasiconcave utility function $u(c, q)$ defined over consumption $c$ and housing space in square meters, $q .^{2}$ All households work in the Central Business District (CBD) and commute to work on a dense radial road system. A household living at $r \mathrm{~km}$ from the CBD incurs two-way commuting costs of $t r$. The rent per square meter of housing is denoted by $p$.

Consumers maximize utility by choice of $c$ and $q$, subject to the budget constraint

$$
w-t r=c+p q
$$

All households are freely mobile within cities, and dwellings are allocated to the highest bidder. Together with household utility maximization, this gives the household's bid rent function $p(w, t, r, u)$ and the optimal dwelling size $q(w, t, r, u)$. These have well known properties, in particular, $p_{r}, p_{u}<0, q_{r}, q_{u}>0$ (see Brueckner, 1987). ${ }^{3}$ Bid rent falls with distance from the CBD to compensate households for commuting costs. If housing is a normal good, bid rent also falls with an increase in $u$ (ultimately, $u$ is endogenously determined in the urban equilibrium). Mirroring this is the response of housing consumption, which rises with $r$ and $u$ because of the lower price.

Housing is produced by profit maximizing firms, using capital and land under constant returns. The production function for floor space in intensive form is $h(S)$, where $S$ is the capital-land ratio (structural density), and is increasing and concave. Since $h(S)$ gives housing per unit of land, it can be interpreted as floor-area ratio (FAR, Bertaud and

\footnotetext{
${ }^{2}$ In Section 5, I introduce pollution externalities into the model to study the welfare effects of building height restrictions.

${ }^{3}$ Subscripts denote partial derivatives.
} 
Brueckner, 2005). Firms maximize profits

$$
\pi=p h(S)-i S-R
$$

where $i$ is the (spatially invariant) price of capital. Together with the zero profit condition for firms, profit maximization gives structural density $S(w, t, r, u)$ and land rent $R(w, t, r, u)$. It can be shown that $S_{r}, S_{u}<0, R_{r}, R_{u}<0$ : since the price of housing falls with $r$ and $u$, firms respond by using less capital per unit of land. Land rent must then also fall.

The city is circular and extends from 0 to the endogenous city border $\bar{r}$. At each radius $r$, the land available for housing is given by $\theta r \leq 2 \pi r$. Without a building height restriction, the equilibrium in the city is given by the two conditions

$$
\begin{aligned}
\int_{0}^{\bar{r}} \frac{h(S(r, u))}{q(r, u)} \theta r d r & =N \\
R(\bar{r}, u) & =R_{A}
\end{aligned}
$$

where $R_{A}$ is the agricultural land rent. Eq. (3) states that the integral over all distances of the population density (total floor space $h$ divided by dwelling size per household $q$ ) equals the (exogenous) number of residents. ${ }^{4}$ Eq. (4) requires that the land rent paid by the housing construction firm at the endogenous city border $\bar{r}$ equals the agricultural land rent. These two equations determine the city border $\bar{r}$ and residents' utility level $u$ as a function of the model's parameters.

I now introduce pollution into the model. There are two sources of pollution: commuting and residential energy and electricity use. ${ }^{5}$ The emissions from commuting are proportional to the total $\mathrm{km}$ of commuting distance traveled and the emissions from residential energy and electricity use are proportional to total floor space in the city. Although pollution may refer to any kind of emissions such as particulate emissions, in the following I will refer to emissions of greenhouse gases (GHGs) for concreteness. Total emissions from

\footnotetext{
${ }^{4}$ In fact, $h / q$ gives the number of households per square meter, which equals population density divided by the number of persons per household.

${ }^{5}$ Other urban drivers include manufacturing production and goods transport (Borck and Pflüger, 2013; Gaigné et al., 2012) and land use (Legras and Cavailhès, 2012). However, commuting and housing are clearly major drivers of urban GHG emissions (Glaeser and Kahn, 2010) so concentrating on these seems reasonable.
} 
commuting, $E^{C}$ and from residential energy use, $E^{H}$, are given by:

$$
\begin{aligned}
E^{C} & =\delta^{C} \int_{0}^{\bar{r}} r \frac{h(S(r, u))}{q(r, u)} \theta r d r \\
E^{H} & =\delta^{H} \int_{0}^{\bar{r}} h(S(r, u)) \theta r d r
\end{aligned}
$$

where $\delta^{C}$ and $\delta^{H}$ are conversion factors that convert $\mathrm{km}$ travelled or square meters of housing into GHG emissions.

Now, as in Bertaud and Brueckner (2005), consider the introduction of a building height limit. This takes the form of a restriction on the floor-area ratio (FAR), which in the model is approximated by $h(S)$. The maximum FAR is denoted by $\hat{h}$, so that the FAR limit is $h(S(r, u)) \leq \hat{h}$ for all $r$. This adds an additional equilibrium condition, namely that there is a value $\hat{r}$ where the equilibrium FAR equals the FAR limit. The equilibrium conditions under the FAR limit are then:

$$
\begin{aligned}
\int_{0}^{\hat{r}} \frac{\hat{h}}{q(r, u)} \theta r d r+\int_{\hat{r}}^{\bar{r}} \frac{h(S(r, u))}{q(r, u)} \theta r d r & =N \\
h(S(\hat{r}, u)) & =\hat{h} \\
R(\bar{r}, u) & =R_{A} .
\end{aligned}
$$

From the results of the model, $S(r, u)$ is decreasing in $r$, so the FAR limit is binding only within the inner city, between 0 and $\hat{r}$, where developers would like to build taller buildings.

Total commuting and housing are now given by

$$
\begin{aligned}
C & =\int_{0}^{\hat{r}} r \frac{\hat{h}}{q(r, u)} \theta r d r+\int_{\hat{r}}^{\bar{r}} r \frac{h(S(r, u))}{q(r, u)} \theta r d r \\
H & =\int_{0}^{\hat{r}} \hat{h} \theta r d r+\int_{\hat{r}}^{\bar{r}} h(S(r, u)) \theta r d r
\end{aligned}
$$

and total emissions are again found by multiplying by the relevant conversion factors.

The effects of the FAR restriction can now be analyzed. For further reference, the following result summarizes the findings by Bertaud and Brueckner (2005).

Proposition 1 A reduction of the FAR limit $\hat{h}$ leads to urban sprawl (an increase in $\bar{r}$ ) and reduces utility $u$.

Proof. See Appendix B. 


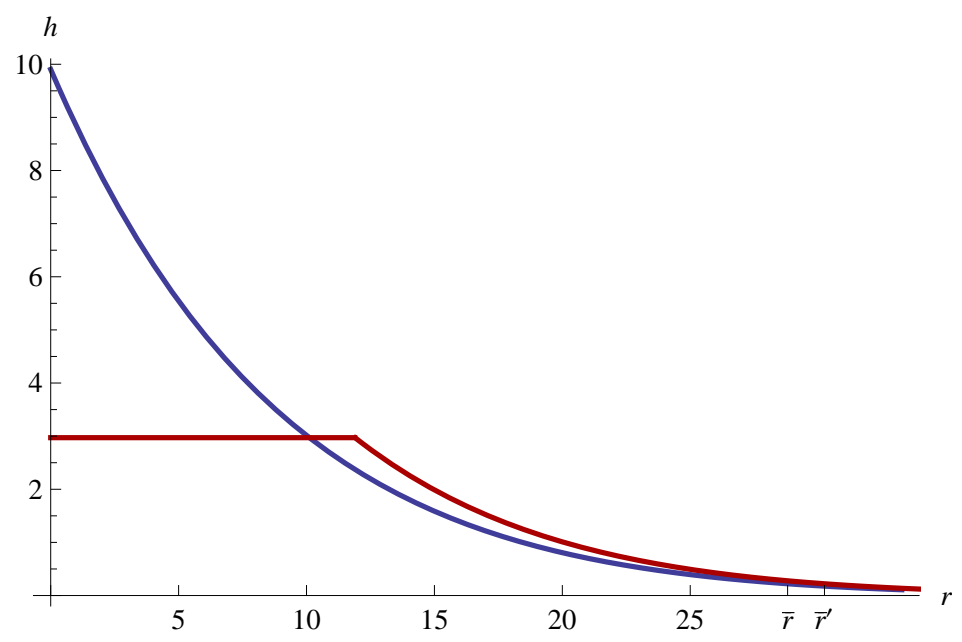

Figure 1: Effect of FAR limit on housing production

Fig. 1 shows the effect of the FAR limit on the spatial expansion of the city. Here and below, the blue curve represents the unrestricted equilibrium and the red curve shows the equilibrium under FAR limit. Since housing production is artificially constrained in the city center, development is pushed to the suburbs, which increases sprawl. Utility falls, since until now I have assumed that environmental externalities do not affect utility. Moreover, the actual level of floor space decreases in the range where the FAR limit is binding and a little further out, and increases in the outskirts. As a result of the artificial limitation of housing supply, rent per square meter increases everywhere in the city and residents demand smaller dwellings (see Figs. 2 and 3). Consequently, population density falls in the inner city and increases in the suburbs (Fig. 4).

It is now straightforward to analyze the effect of the FAR limit on GHG emissions. This is summarized in the next result.

Proposition 2 A reduction in the FAR limit $\hat{h}$ increases emissions from commuting in the city. The effect on total housing is ambiguous in general, but a small decrease in the FAR limit, starting at $k=1$ increases emissions from housing.

Proof. See Appendix B.

First, average commuting distance increases on two counts: the city expands spatially, and the density gradient becomes flatter (see Fig. 4), so the mass of households with 


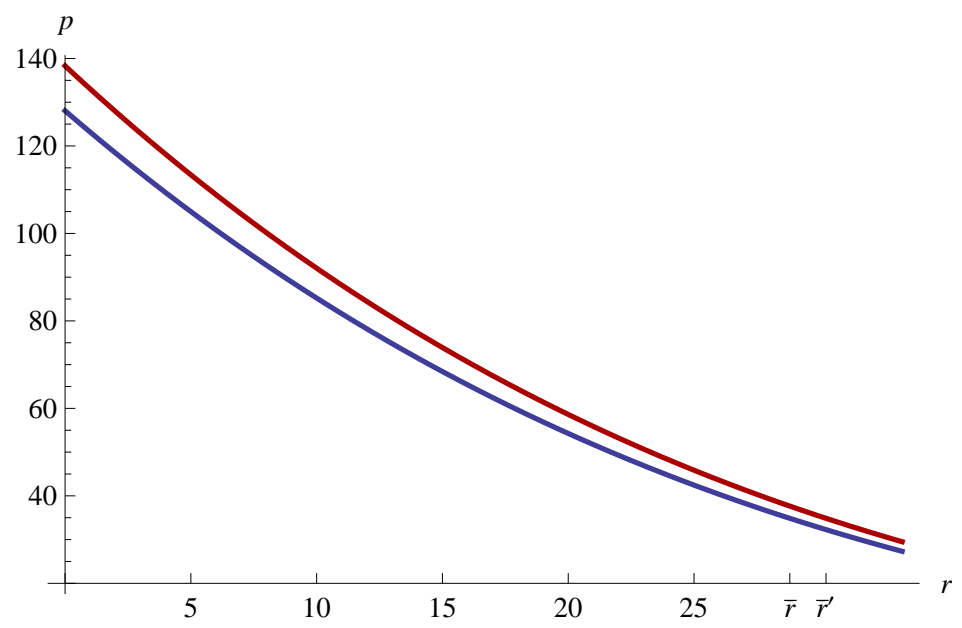

Figure 2: Effect of FAR limit on housing prices

relatively long commutes increases. Therefore, GHG emissions from transport increase.

Second, however, Fig. 1 suggests that the total amount of floor space in the city may decrease. Prop. 2 shows that this may or may not be the case. Two effects are at work. First, tightening the FAR limit reduces housing production in the city center, which tends to reduce total housing. Second, however, by increasing city size, the tighter limit adds housing at the city outskirts. A priori, the total effect is ambiguous.

The net effect of tightening the FAR limit on GHG emissions is therefore ambiguous and depends, among other things, on the fuel efficiency of the commuting mode and the energy efficiency of home appliances. To shed some light on the quantitative nature of the trade-off, in the next section, I will simulate the equilibrium numerically, and use published GHG conversion factors for transport, heating, and electricity use, to study whether an FAR limit may actually increase or decrease total GHG emissions.

\section{Numerical simulation}

In this section, I use specific functional forms and parameters and solve the model numerically. Parameters are partly chosen from the literature and partly from published sources to replicate key values for housing and commuting in German cities. Data sources are described in Appendix A. 


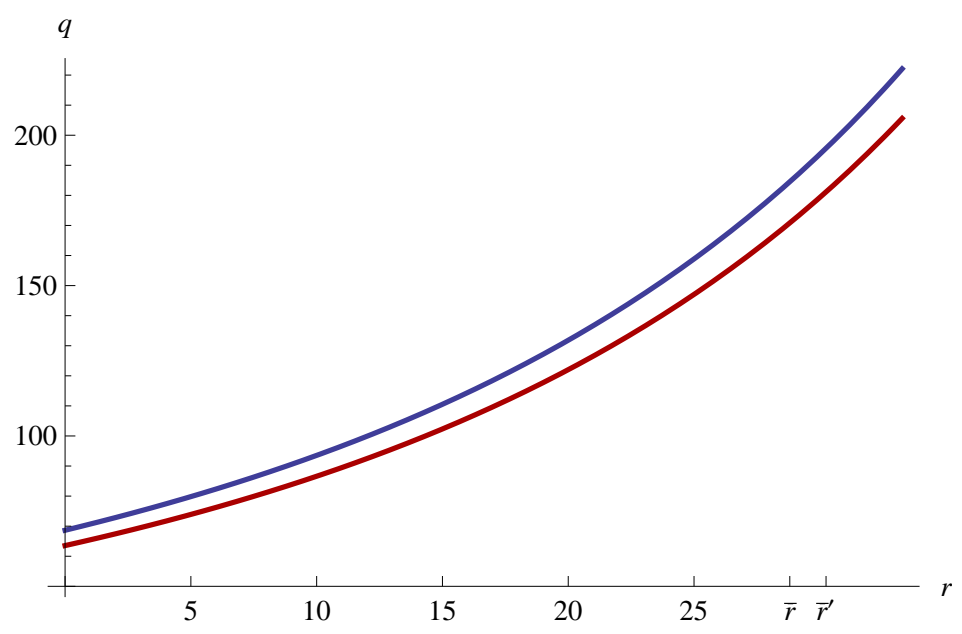

Figure 3: Effect of FAR limit on dwelling sizes

Utility is assumed to be Cobb-Douglas:

$$
u=(1-\alpha) \log c+\alpha \log q
$$

Following Davis and Ortalo-Magné (2011) I set the budget share of housing to $\alpha=0.24$. This gives housing demand $q=\alpha(y-t r) / p$ and the bid rent function

$$
p(r, u)=(y-t r)^{\frac{1}{\alpha}} u^{-\frac{1}{\alpha}}
$$

Income is net annual household income, for which I take the German average value of EUR 36624. Commuting costs are made up of monetary and time costs of commuting and are set to 341 EUR per year. City population is set to $N=500,000$ households. ${ }^{6}$

Housing production is also assumed to be Cobb-Douglas, $h(S)=\gamma S^{\beta}$ as in Bertaud and Brueckner (2005). Solving the firm maximization problem gives

$$
\begin{aligned}
& S(r, u)=\beta^{\frac{1}{1-\beta}} \gamma^{\frac{1}{1-\beta}} v^{\frac{1}{a(\beta-1)}}(y-t r)^{\frac{1}{a-a \beta}} \\
& R(r, u)=\left(\beta^{\frac{\beta}{1-\beta}}-\beta^{\frac{1}{1-\beta}}\right) \gamma^{\frac{1}{1-\beta}} v^{\frac{1}{a(\beta-1)}}(y-t r)^{\frac{1}{a-a \beta}} .
\end{aligned}
$$

In the benchmark simulation, I set $\gamma=0.00035$ and $\beta=0.745$. Solving the unrestricted equilibrium gives $\bar{r}=28.8, v=1037.08$, which implies an average commuting distance of $10.96 \mathrm{~km}$, which fits the average commuting distance of German households. Units of $q$

\footnotetext{
${ }^{6}$ With an average household size of 2 , this would be a city with one million inhabitants.
} 


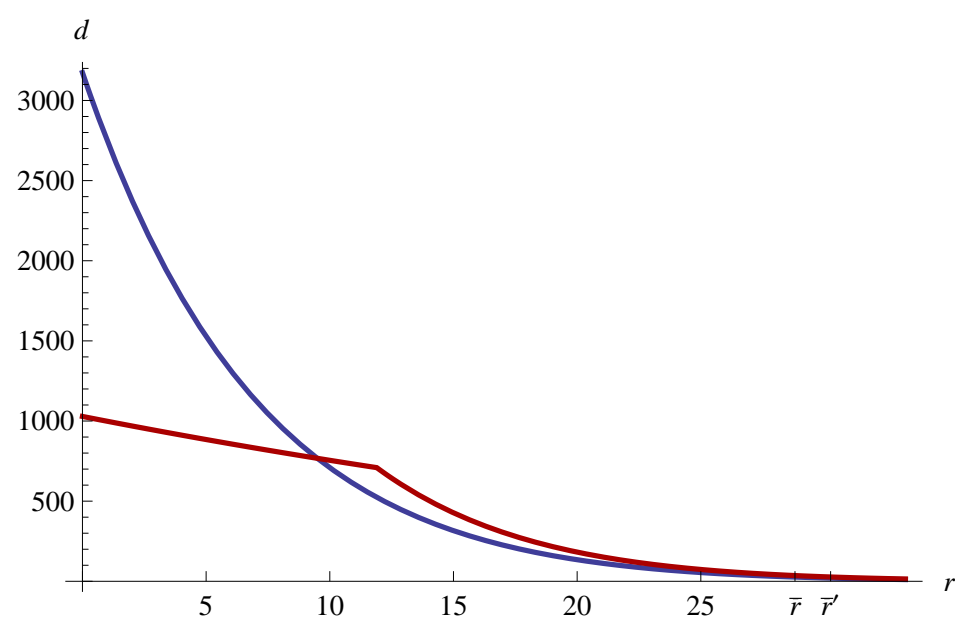

Figure 4: Effect of FAR limit on population density

are chosen such that the average dwelling size is $99.7 \mathrm{~m}^{2}$ and rises from $68.64 \mathrm{~m}^{2}$ at the CBD to $184.52 \mathrm{~m}^{2}$ at the city border. The price of housing falls from $128.05 \mathrm{EUR} / \mathrm{m}^{2}$ annually (10.67 EUR per month) at the CBD to $34.86 \mathrm{EUR} / \mathrm{m}^{2}$ (2.90 per month) at the city border. The FAR is shown in Fig. 1 and falls from 9.9 at the CBD to 0.22 at the city border.

The FAR limit is implemented as a fraction of the FAR value at the CBD in the unrestricted city: $\bar{h}=k h(0)$. The equilibrium in the restricted city is then computed by solving (7)-(9) numerically for varying values of $k$.

Total emissions are computed by multiplying total housing in square meters by a conversion factor $\delta^{H}$, which combines information on the total annual energy use in kwh for heating and electricity per square meter and the conversion of one kwh of electricity or heating energy into tons of $\mathrm{CO}_{2}$ equivalents. Likewise, total commuting distances are multiplied by 500 (to get round-trips on 250 workdays) and then by the conversion factor $\delta^{C}$ which converts person-kilometers of commuting (assuming an average mix of commuting modes) into $\mathrm{CO}_{2}$ equivalents. The conversion factors are $\delta^{C}=80(=500 \times 0.16), \delta^{H}=47.79$ (see Appendix A for details).

Figs. 5-7 show the differences in emissions between the restricted and unrestricted equilibria for commuting, $\Delta E^{c}$ and housing, $\Delta E^{h}$, and total emissions, $\Delta E$, as a function of $k$. As can be seen, FAR limits, no matter how strict, always increase emissions from commuting. This simply follows from the finding that the FAR limit leads to urban sprawl and decreases the average population density in the city (see Prop. 1 and Bertaud and 


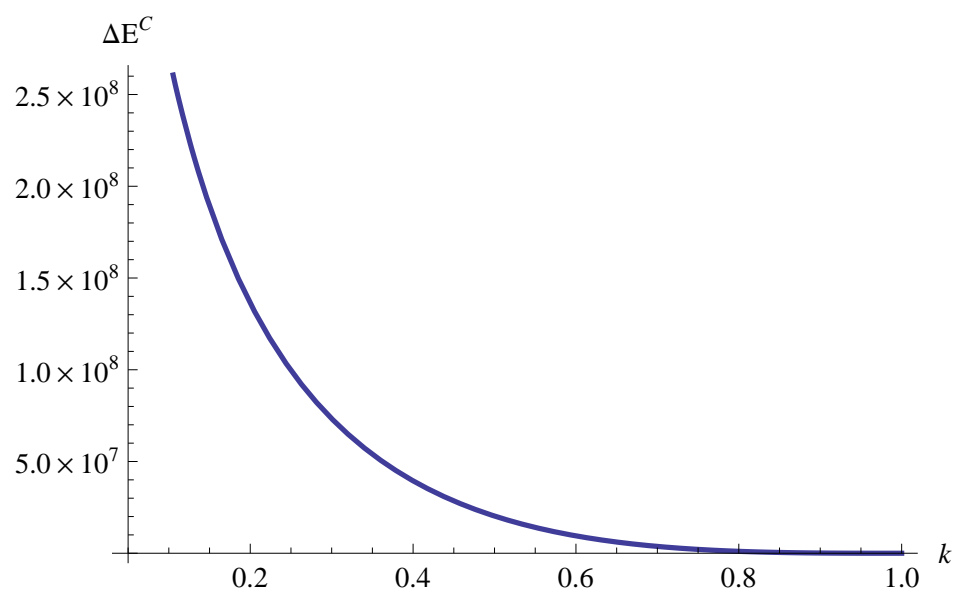

Figure 5

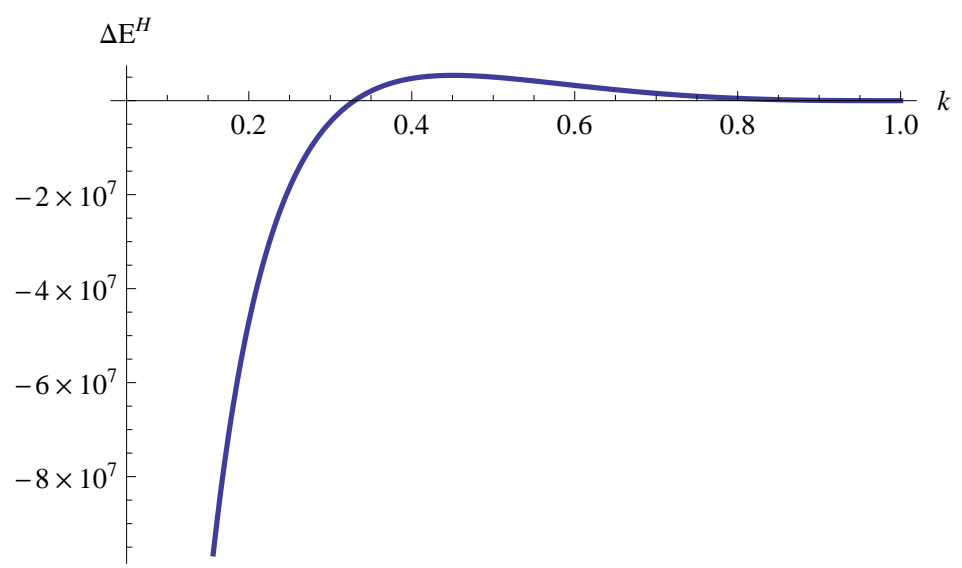

Figure 6

Brueckner, 2005). The increase in emissions is more pronounced the stricter the FAR limit, and vanishes as $k \rightarrow 1$.

For housing emissions, Fig. 6 shows that total emissions rise with a stricter FAR limit (lower $k$ ) for low to middle values of $k$. However, when the FAR limit becomes very strict, total emissions from residential energy use decrease with further tightening of the limit. The intuition for this is the following. As Fig. 1 shows, the FAR limit decreases total floor space at distances close to the CBD and increases housing production further out in the city. But these changes have to be multiplied by $\theta r$ to get the change in total floor space at distance $r$. Since land is more abundant at the city border, the increase in housing production far away from the CBD is larger than close to the CBD simply because there is 


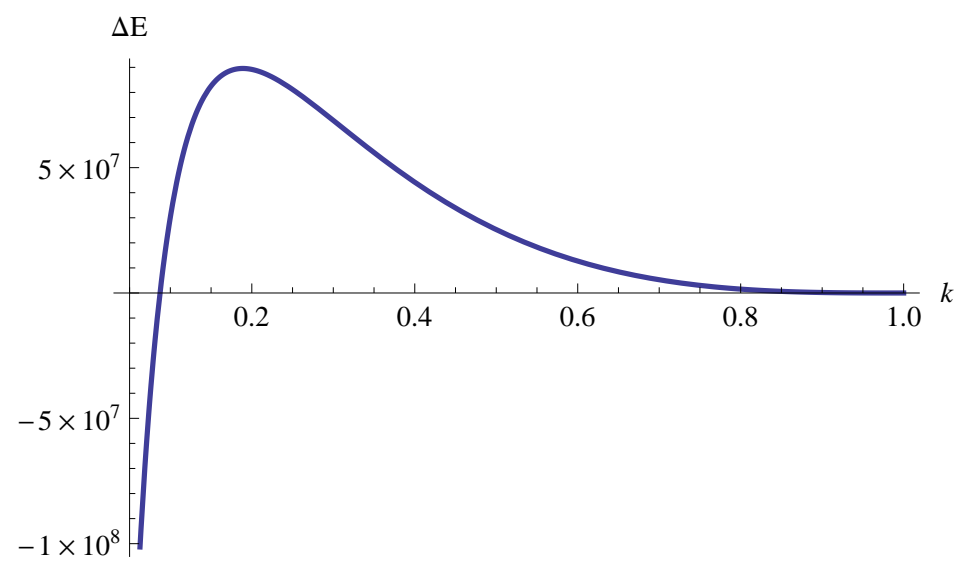

Figure 7

more land. Intuitively, when the FAR restriction is not very tight, there is a small reduction of housing in the center, which is outweighed by the additional housing production at the outskirts. When the limit becomes strict enough, however, $\hat{r}$ moves farther and farther out. Then, the decrease of housing production close to the CBD applies to a larger area and outweighs the increase in housing production in the suburbs. As a result, with the parameters used, total emissions also fall when $k$ is low enough, see Fig. 7 . This is the paper's first result: it is possible that limiting building heights can actually reduce GHG emissions from residential energy use, possibly so much so that total GHG emissions in the city fall. The figure also shows, however, that the value of $k$ which makes total emissions decrease is low: 0.09 in the example, which gives an FAR of 0.87 (compared to 0.22 at the city border). Further, Prop. 2 and Fig. 7 make clear that the introduction of a small FAR limit, starting from no limit $(k=1)$ increases total emissions.

Fig. 7 also shows a potential problem of building height limits, in particular, emissions are not monotone in the strictness of the limit. In fact, total emissions increase by 3 percent when $k$ is reduced to 0.19 before emissions fall. For a low value of $k=0.05$, total emissions fall by 7 percent. The inverted U-shape of the graph in Fig. 7 also implies that welfare is not concave in the strictness of the FAR limit, so the welfare optimal policy might be either a very strict limit or no limit at all (see Section 5). 


\section{Extensions}

\subsection{Urban heat islands}

Until now, emissions from residential energy use were assumed to be a simple linear function of total housing. However, the urban structure itself may influence the city climate and hence, the demand for residential energy. Cities are generally warmer than their rural surroundings, an effect known as urban heat island (UHI) effect. Moreover, the UHI is affected by the built environment of the city. UHI effects imply that city residents will generally demand more energy for cooling by air conditioning during summer and less energy for heating in winter. Whether on balance, total energy demand during a year rises or falls depends on many factors, including the city's average temperature: cities in tropical climates would probably demand more energy as a result of UHIs (since increased demand for cooling would tend to outweigh reduced demand for heating) while the converse would tend to hold in cities in colder climates.

In this section, I concentrate on the relation between urban canyon geometry and the UHI (see Oke, 1981). Canyon geometry is measured by the sky-view factor, a measure of the amount of sky visible when viewed from the ground. The sky-view factor can be approximated by the ratio of height of buildings to the width of urban canyons (i.e. width of streets). On the one hand, taller buildings and narrow streets (low sky-view factor) increase shade, which reduces the UHI during the day. On the other hand, a low sky-view factor (large height-to-width ratio) reduces (natural) nighttime cooling. Since the UHI is typically largest at night, it is sensible to assume that the UHI increases with building height (Oke, 1981). The total effect on energy demand and GHG emissions then depends, among other things, on the local temperature.

I use the following building blocks to model the UHI. First, using data provided in Oke (1981), I estimate the local temperature $T^{U}$ in the city center as a function of (a) the local rural temperature $T^{R}$ and (b) the ratio of building height to canyon width $(H / W)$ in the urban center (see Appendix A for details). This results in the following relationship: ${ }^{7}$

$$
T^{U}=8.99+4.49 \ln \left(\frac{H}{W}\right)-0.13 T^{R}
$$

Second, using the data from OECD countries in Bessec and Fouquau (2008), I estimate a quadratic function of monthly per capita energy demand $d$ against monthly average

\footnotetext{
${ }^{7}$ All variables are significant at $1 \%$.
} 


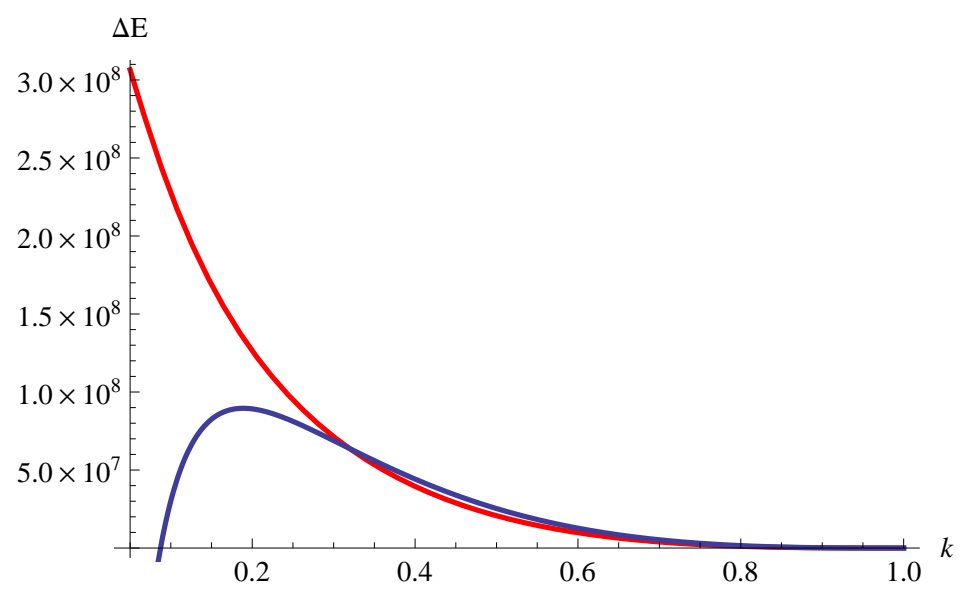

Figure 8: Effect of FAR limit on GHG emissions with and without UHI

temperature (controlling for country fixed effects). This gives the following functional form (see Appendix A for details):

$$
d=0.19-0.001 T+0.00004 T^{2}
$$

This function is U-shaped with a minimum at 18.2 degrees $\mathrm{C}$.

Inserting (15) into (16) then gives a relation between energy use and building height. Fig. 8 shows the effect of the UHI. The blue curve replicates Fig. 7. The red curve shows the emissions difference for varying degrees of $k$, assuming a UHI and a local temperature of $15^{\circ} \mathrm{C}$. Apparently, with the UHI, emissions do not increase as strongly with an FAR limit when this is not too strict. Further, emissions are actually reduced by the FAR limit for a higher (less strict) value of the FAR limit, so in this sense, it seems that the UHI reinforces the beneficial effect of FAR limits. When the limit gets sufficiently strict, however, the UHI actually reduces the reduction of emissions implied by the FAR limit.

Exactly how the UHI effect influences GHG emissions depends on local climate. In cold climates, the reduced heating implied by rising urban temperatures will outweigh the increased cooling. Hence, energy demand is likely to be lower with a UHI effect than without when the local temperature is low. With the data and specifications used here, however, the general shape of Fig. 8 does not vary with the local temperature. ${ }^{8}$

\footnotetext{
${ }^{8}$ This statement is subject to qualification. In particular, more detailed data (for instance, use of individual instead of country data, more detailed UHI and city structure data, and use of monthly instead of annual temperatures), might change the picture.
} 


\subsection{Transport mode choice}

This section looks at how including transport mode choice affects the analysis. For simplicity and to focus on transport emissions, I now assume that each resident consumes exactly one unit of housing so total housing and residential energy use are fixed. The FAR, however, still varies according to the same housing production function as above.

Transport mode choice is introduced into the urban model as in LeRoy and Sonstelie (1983), Sasaki (1990) and Borck and Wrede (2008).

Individuals can now commute by public transport (bus, for short), indexed $B$ or by car, indexed $A$. Using mode $i$ incurs a fixed cost of $F_{i}$ and a variable cost of $t_{i}$ per $\mathrm{km}$, where I assume $F_{A}>F_{B}=0$ and $t_{A}<t_{B}$, so cars have higher fixed cost and lower variable costs. Since dwelling size is fixed, individual utility is now given by consumption:

$$
u=w-F_{i}-t_{i} r-p_{i},
$$

for $i=A, B$. An individual will drive by car if and only if

$$
r>\tilde{r} \equiv \frac{F_{A}-F_{B}}{t_{B}-t_{A}}
$$

This gives rise to the households' bid rent $p(r, u)=\max \left\{p_{A}(r, u), p_{B}(r, u)\right\}$.

The model is then solved like before. While multiple equilibrium configurations are possible (see, e.g. Borck and Wrede, 2008), I concentrate on the equilibrium where some households commute by bus (those living close enough to the CBD) and some (living farther from the center) by car.

Total emissions from commuting, in the case of the FAR limit, are now given by

$$
C=c_{B} \int_{0}^{\tilde{r}} r \hat{h} \theta r d r+c_{A}\left(\int_{\tilde{r}}^{\hat{r}} r \hat{h} \theta r d r+\int_{\hat{r}}^{\bar{r}} r h(S(r, u)) \theta r d r\right)
$$

Note that this assumes that the thresholds where households are indifferent between commuting by bus or car lies within the zone where the FAR limit binds, which obviously need not be the case $^{9}$

For the numerical simulation, I now use slightly different parameters, in particular, $\gamma$ is set to 0.07 to get plausible values despite the exogenous housing consumption. The cost

\footnotetext{
${ }^{9}$ For simplicity, I study only this one case here. The case where $\tilde{r}$ is greater than $\hat{r}$ can be treated analogously.
} 
parameters are $t_{A}=295, t_{B}=367, F_{A}=750, F_{B}=0$. As a result, everyone living beyond $\tilde{r}=10.42$ commutes by car. The unrestricted equilibrium has $v=25473.1, \hat{r}=28.47$. To illustrate the FAR limit, as before, $\hat{h}$ is set to $k h(S(0, u))$, i.e. to a multiple of the maximum FAR in the unrestricted case. For $k=0.25$, we get $\hat{r}=26.11, \bar{r}=34.32, v=23745.7$. The lower density gradient implies that more people now commute by car. Whereas the fraction of all households commuting by bus is $29.9 \%$ in the unrestricted city, it is only $11 \%$ in the restricted city.

The conversion factors for automobiles are 0.2086 tons $\mathrm{CO}_{2} \mathrm{e} / \mathrm{km}$ and for public transit 0.1112 tons $\mathrm{CO}_{2} \mathrm{e} /$ passenger $\mathrm{km}$ (which is the average of the values for underground and local bus). Suppose that the conversion factors for both modes were the same, namely, the average of both values, 0.1599 . This would imply an increase in emissions from commuting due to the FAR of $105 \%$. Using the actual values $c_{A}=0.2086, c_{B}=0.1112$ on the other hand leads to an emissions increase of $110 \%$. Thus, the negative effect of the FAR limit is amplified by endogenous mode choice.

FAR limits thus influence transport mode choice and have further effects on GHG emissions. The effect studied here stems simply from the fact that with the FAR more households commute by car, since housing development is pushed towards the outskirts. There may be other effects which reinforce this finding. For instance, if there are significant economies of scale in public transit, the average costs per user would decline with the number of users. But then, the reduction in transit users caused by an FAR limit would be even stronger, since rising costs would further reduce ridership. There are several well known reasons for increasing returns, most prominently, high fixed costs - e.g. for underground systems - and increasing returns due to the Mohring effect (increased usage leads to increased service frequency which reduces average waiting times). In summary, when the elasticity of transit users with respect to population density is large, the increase in emissions from commuting will be magnified.

\section{Welfare}

Bertaud and Brueckner (2005) calculate the welfare loss resulting from building height restrictions in a model without environmental externalities. Since the urban equilibrium is efficient under these assumptions, an FAR limit must reduce welfare. The purpose of this section is to weigh the distortion created by the interference with the housing market equilibrium against the potential gain implied by the reduction of environmental 
externalities. In other words, the goal is to study whether there is an optimal level of FAR limits. The first best policy would just internalize the marginal damage created by commuting and residential energy use through (differentiated) carbon prices. However, if such prices do not exist for political reasons, then governments might use second-best policies such as the land use policies studied here or in Larson et al. (2012), Joshi and Kono (2009) and Kono et al. (2012).

To study the welfare effects of building height restrictions, I now assume that utility is of the form

$$
u=(1-\alpha) \log c+\alpha \log h-\mu \log E, \quad \mu>0,
$$

where $E$ are total emissions from commuting and residential energy use, calculated as before.

Note that I am assuming that utility is a function of local emissions. This ignores the fact that climate change is a global phenomenon. Thus it is best to think of $\mathrm{CO}_{2}$ emissions from other places as given. It may also be that residents care about the GHG emissions in their city even if the effect on global climate is small. This seems likely since many cities do have climate action plans aimed at reducing local emissions. ${ }^{10}$

I use the parameters from section 3 , together with $\mu=3$ without the UHI. ${ }^{11}$ Fig. 9 shows indirect utility as a function of $k$. As the Figure shows, an FAR restriction may actually be welfare improving. The optimal FAR restriction balances two effects. On the one hand, it distorts the housing market, on the other one, it reduces emissions (at least over a certain range, as shown in Fig. 7). Depending on the strength of the environmental damage, total welfare may thus rise or fall with a tighter FAR limit. Fig. 9 shows the case of $\mu=3$, where the FAR is welfare improving. On the other hand, Fig. 10 shows the case $\mu=0.1$. If the marginal damage is low, then the effect of reduced emissions is dominated by the housing market distortions, and city residents would not be willing to impose an FAR limit.

Note that in general, utility is not concave in $k$. The reasoning behind this is as follows. When $\mu$ is close to zero, Fig. 9 shows that utility is concave and falls with the strictness of the FAR limit. When $\mu$ is large enough, this effect has to be weighed against the effect on emissions. As Fig. 7 shows, emissions first increase and then decrease, and eventually decrease sharply as the FAR limit becomes successively stricter. Hence, utility first falls

\footnotetext{
${ }^{10}$ If, however, residents think that local GHG emissions do not affect global climate, $\mu$ should be set to zero, and the FAR limit would always reduce welfare.

${ }^{11}$ The utility plots look similar with UHI. Since utility is not concave in $k$ and interior optima do not obtain, I do not compare the policies with and without UHI here.
} 


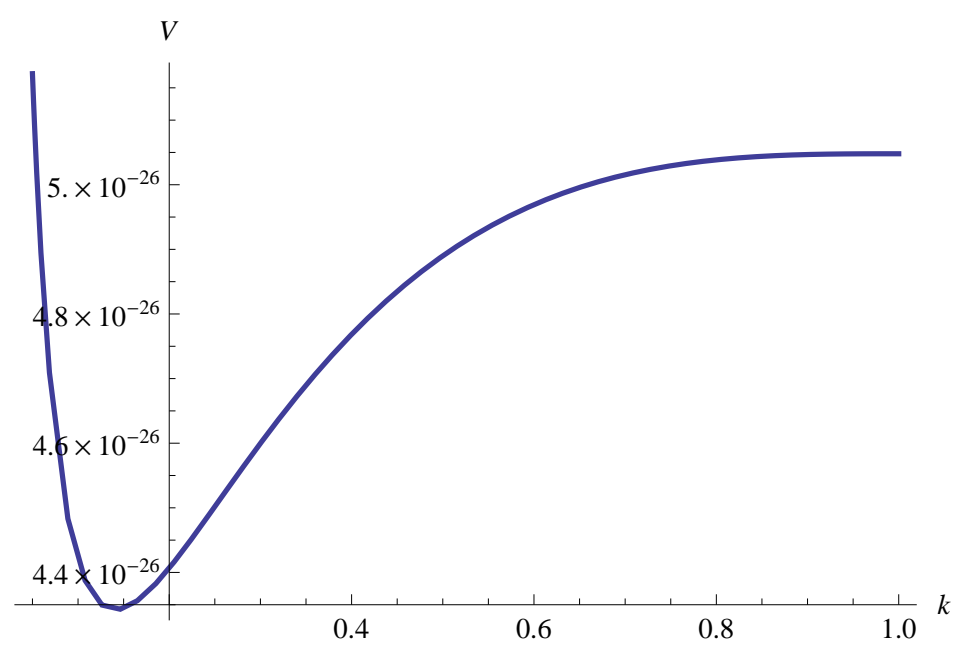

Figure 9: Utility as function of $k(\mu=3)$

\begin{tabular}{rrrrrrr}
\hline & Benchmark & $N=250000$ & $R_{A}=21636$ & $t=170.5$ & $\delta^{C}=32.5$ & $\delta^{H}=23.89$ \\
$\tilde{k}$ & 0.087 & 0.113 & 0.0842 & 0.069 & 0.163 & 0.025 \\
\hline
\end{tabular}

Table 1: Sensitivity analysis

and then rises with gradual tightening of the FAR limit. This implies something of a difficulty for applied welfare analysis. In particular, marginal analysis may not provide the correct welfare measure, and large changes in FAR restrictions may have unexpected welfare effects.

\section{Sensitivity}

In this section, I vary the values of some parameters in order to see how the results are affected. I go back to the simple model without transport mode choice and UHI. In the following, the relevant parameters are all reduced by 50 percent. I concentrate on showing the result of the parameter change for the value of $k$ where emissions just equal emissions without FAR limit, which is denoted $\tilde{k}$. The results are shown in Table 1.

First, I reduce the conversion factor for commuting $\delta^{C}$, i.e. the amount of $\mathrm{CO}_{2}$ emissions per passenger $\mathrm{km}$. This increases $\tilde{k}$. The opposite effect occurs when the conversion factor for residential energy use $\delta^{H}$ is reduced. The intuition here is that the conversion factors do not affect the urban equilibrium (as long as utility is independent of emissions). Hence, the only effect of reducing $\delta^{C}$ is to reduce the value of emissions from commuting relative 


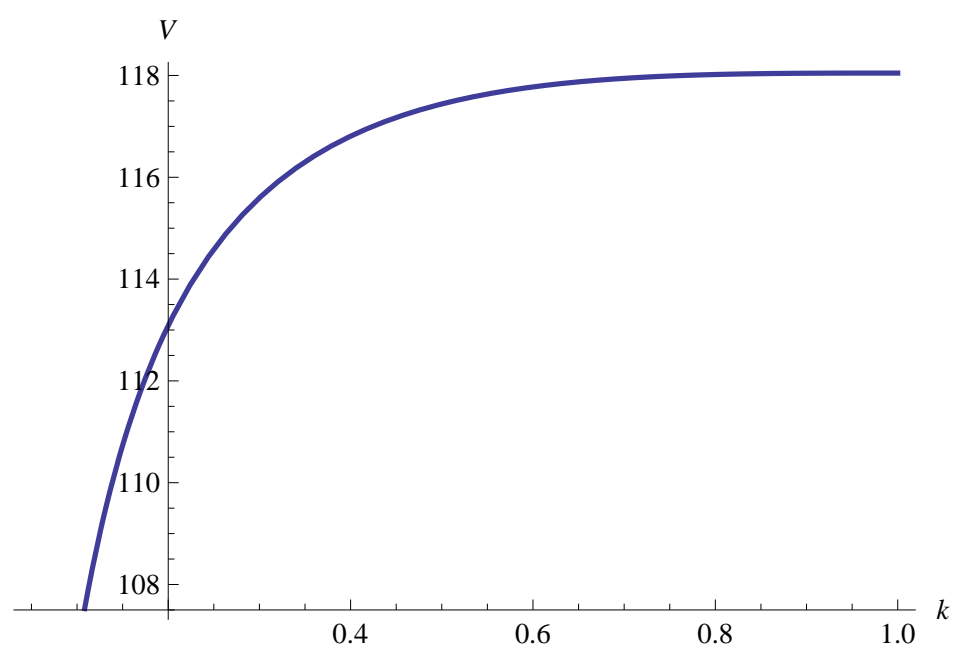

Figure 10: Utility as function of $k(\mu=0.1)$

to emissions from housing. Since commuting emissions rise with a decrease in $k$, this reduction increases the threshold value of $k$.

Changing the other parameters changes the results through the effect on the urban equilibrium. Tab. 1 shows that reducing the number of households to 250,000 increases $\tilde{k}$. A smaller population leads to smaller spatial expansion of the city and lower population density in the unrestricted city. When an FAR limit is introduced, commuting increases, as sprawl shifts residents to the outskirts of the city. However, due to the lower density, this effect is much less pronounced than in a large city.

The reduction of agricultural land rent has only a small effect on $\tilde{k}$. This is interesting, since the reduction of $R_{A}$ has a large effect on the size of the unrestricted city. However, it turns out that the effect on changes in emissions from commuting and housing implied by the FAR is negligible.

Reducing commuting costs to half their original value leads to a decrease of $\tilde{k}$. Reduced commuting costs also lead to a spatial expansion of cities, as residents are willing to bear longer commutes in exchange for cheaper housing at the city outskirts. When the FAR limit is introduced, the increase in emissions from commuting becomes much more pronounced when commuting costs are low, and hence, total emissions increase for a larger range of $k$. 


\section{Conclusion}

The paper has considered the effect of building height restrictions on environmental emissions emanating from urban commuting patterns and residential energy use. In particular, I have shown that FAR limits can potentially decrease total emissions. While on the one hand, FAR limits lead to urban sprawl and thereby increase commuting in a city, on the other hand, increased competition for inner city land raises housing prices and may reduce the total demand for housing. In sum, total emissions may fall. The paper has shown, however, that this cannot occur when a light FAR limit is introduced in an unrestricted city, and emissions are most likely to fall when the building height limit is already very tight.

The paper has also shown how the results depend on the choice of commuting mode and the urban heat island effect. These seem to be important facets impacting urban structure and climate.

Second, the paper has also shown that an FAR limit may increase total welfare. This depends on whether the reduction of environmental externalities outweighs the welfare loss caused by the distortion of a competitive housing market. Since residents' welfare is not concave in the tightness of the FAR limit, it may be that either very strict limits or no limit at all are welfare optimal. It should be noted, however, that the analysis assumes that housing is malleable and policy measures influence building heights and city structure. Thus, it is best to think of the results as the long-run effects of policy. Alternatively, when cities are planned, applied welfare analysis of the kind used here may be used to assess the impact of alternative urban policies.

The analysis in the paper has been simple in some respects. Further research may show how changing some assumptions will change the results. Among other things, one might study an integrated model with endogenous housing, endogenous transport mode choice, and UHI. Also, including emissions from other urban activities and analyzing different functional forms suggest themselves as avenues for further research. 


\section{Appendix}

\section{A Data and estimation}

\section{A.1 Data sources}

Net household income in Germany in 2011 was 3052 EUR per month or 36624 EUR per year. See www.destatis.de.

Commuting costs are calculated as follows. The hourly wage is set to 17 EUR (see Krause et al., 2010). Travel time is valued at $50 \%$ of the wage (Small, 2012) or 8.50 per hour. At a speed of $30 \mathrm{~km} / \mathrm{h}$ this gives an hourly time cost of 0.283 EUR per $\mathrm{km}$. Adding 0.45 EUR operating costs gives 0.733 EUR/ $\mathrm{km}$. Multiplying by 0.62 workers per household and by 250 work days per year and by 2 to get round trip costs gives 227 EUR per $\mathrm{km}$ per year. This is finally multiplied by 1.5 to adjust for non-work trips to get $341 \mathrm{EUR} / \mathrm{km}$ per year.

The agricultural land rent is calculated from www.destatis.de. The median sale value of agricultural land in Germany is 14424 EUR per hectare. Since the sale price is assumed to be given by $R_{A} / r$, where $r$ is the interest rate, this value is multiplied by $r=0.03$ and by 100 to give a value of 43272 EUR per square $\mathrm{km}$.

The conversion factors are taken from the Carbon Trust, see www.carbontrust.com. For commuting, I use the values for petrol cars $\left(0.2086\right.$ tons $\left.\mathrm{CO}_{2} \mathrm{e} / \mathrm{km}\right)$ and the average value for public transit $(1 / 2 \times$ value for bus [0.1488 tons per passenger $\mathrm{km}]+1 / 2 \times$ value for subway [0.0736 tons per passenger $\mathrm{km}]$ ) and bicycle/foot (0 tons) weighted by modal shares of $45 \%$ for cars, $35 \%$ for public transit and $20 \%$ for bicycle/foot to get 0.13 tons $\mathrm{CO}_{2}$ e per passenger km. Multiplying by 500 (250 working days times 2 to get annual round trip values) gives a factor of 80 .

Data for housing are from www.destatis.de. Average dwelling size in 2010 was 92.1 $m^{2}$ and average gross monthly rent $6.87 \mathrm{EUR} / \mathrm{m}^{2}$ or $82.44 \mathrm{EUR} / \mathrm{m}^{2}$ annually. Average commuting distance is $11.5 \mathrm{~km}$ per day, taking values from various tables in Infas and DLR (2010).

For residential energy use, I use values on dwelling sizes, heating and electricity use from RWI and forsa (2013). According to this source, households in single-family homes use $131.6 \mathrm{~m}^{2}$ of space on average, $30.35 \mathrm{kwh} / \mathrm{m}^{2}$ of electricity and $149.4 \mathrm{kwh} / \mathrm{m}^{2}$ for heating; the corresponding figures are $76.6 \mathrm{~m}^{2}, 32.3 \mathrm{kwh} / \mathrm{m}^{2}$ electricity use and $128.1 \mathrm{kwh} / \mathrm{m}^{2}$ for heating in multi-family houses. The conversion factors are $0.5246 \mathrm{CO}_{2} \mathrm{e} / \mathrm{kwh}$ for electricity, 
$0.2468 \mathrm{CO}_{2} \mathrm{e} / \mathrm{kwh}$ for burning oil and 0.1836 for natural gas. I use the weighted average of these (weighted by $67 \%$ use natural gas and $33 \%$ oil) and multiply by the average energy/electricity use to get a total figure of 47.79 tons $\mathrm{CO}_{2} \mathrm{e} / \mathrm{m}^{2}$ from residential energy use.

\section{A.2 Energy demand and UHI estimation}

For the estimation of the relationship between UHI and urban structure, I use the data from Oke (1981). Oke (1981) provides data for the maximum urban heat island intensity $\Delta T$ and the sky-view factor $\psi$ for a sample of 31 cities. Using the equations provided in Oke (1981),

$$
\begin{aligned}
\psi_{W} & =\frac{1}{2} \frac{\sin ^{2} \Theta+\cos \Theta-1}{\cos \Theta} \\
\psi & =1-2 \psi_{W}
\end{aligned}
$$

where $\psi_{W}$ is the 'wall view factor' and $\Theta=\arctan (2 H / W)$ where $H / W$ is the height to width ratio. Solving for $H / W$ gives

$$
\frac{H}{W}=\frac{\sqrt{1-\psi^{2}}}{2 \psi}
$$

In addition, I collected data for the temperature in the cities in the sample from http://www . weatherbase.com, which I define as the rural temperature. I then regress $\Delta T$ on $\ln (H / W)$ and $T^{R}$ which gives the results in Table A.1.

For the estimation of the relation between energy demand and temperature, I use the data in Bessec and Fouquau (2008). I regress the filtered per capita demand (which results from regressing demand on a third-degree time polynomial and a dummy for the month of August) on temperature and temperature squared, controlling for country fixed effects. Results are shown in Table A.2. 
Table A.1: Regression results: UHI and height-to-width ratio

\begin{tabular}{lr}
\hline Variable & \\
\hline $\log (H / W)$ & $\left(0.489^{* * *}\right.$ \\
& $(0.266)$ \\
$T_{R}$ & $-0.130^{* * *}$ \\
& $(0.0307)$ \\
Constant & $8.992^{* * *}$ \\
& $(0.170)$
\end{tabular}

\begin{tabular}{lr} 
Observations & 31 \\
$R^{2}$ & 0.930 \\
\hline Standard errors in parentheses. \\
$* * * p<0.01, * * p<0.05, * p<0.1$.
\end{tabular}

Table A.2: Regression results: OECD energy demand and temperature

\begin{tabular}{lc}
\hline Variable & \\
\hline Temperature & $-0.00140^{* * *}$ \\
& $(0.000328)$ \\
Teamperature sq. & $3.83 \mathrm{e}-05^{* *}$ \\
& $(1.59 \mathrm{e}-05)$ \\
Constant & $0.191^{* * *}$ \\
& $(0.00215)$ \\
& \\
Observations & 2,880 \\
Number of countries & 15 \\
$R^{2}$ & 0.930 \\
\hline \multicolumn{2}{c}{ Standard errors in parentheses. } \\
$* * * p<0.01, * * p<0.05, * p<0.1$.
\end{tabular}




\section{B Proofs}

Proof of Proposition 1. Equations (7)-(9) define $u, \hat{r}$ and $\bar{r}$ as functions of $\hat{h}$. Differentiating (7)-(9), using (8) and simplifying gives:

$$
\begin{aligned}
& \frac{d u}{d \hat{h}}=\frac{\bar{R}_{r} A}{B}>0 \\
& \frac{d \bar{r}}{d \hat{h}}=-\frac{\bar{R}_{u} A}{B}<0 \\
& \frac{d \hat{r}}{d \hat{h}}=-\frac{\bar{R}_{r} \hat{S}_{u} A}{\hat{S}_{r} B}<0,
\end{aligned}
$$

where $A=\int_{0}^{\hat{r}} \frac{1}{q(r, u)} \theta r d r>0, B=D(\bar{r}, u) \theta \bar{r} \bar{R}_{u}-\bar{R}_{r} \int_{0}^{\bar{r}} D_{u} \theta r d r>0$ and $\bar{R}_{r}=R_{r}(\bar{r}, u)$ and so on. Thus, lifting the FAR limit (increasing $\hat{h}$ ) decreases city size and increases utility. Conversely, tightening the FAR limit increases city size and reduces utility.

Proof of Proposition 2. Let $\hat{D}(\hat{h}, r, u)=\hat{h} /(q(r, u)$ and $D(r, u)=h(S(r, u)) / q(r, u)$. Differentiating (10) and (11) gives:

$$
\begin{array}{r}
\frac{d C}{d \hat{h}}=\int_{0}^{\hat{r}} r\left(\hat{D}_{\hat{h}}+\hat{D}_{u} \frac{d u}{d \hat{h}}\right) \theta r d r+\int_{\hat{r}}^{\bar{r}} r D_{u} \frac{d u}{d \hat{h}} \theta r d r+\bar{r} \bar{D} \theta \bar{r} \frac{d \bar{r}}{d \hat{h}} \\
\frac{d H}{d \hat{h}}=\int_{0}^{\hat{r}} \theta r d r+\int_{\hat{r}}^{\bar{r}} h^{\prime} S_{u} \frac{d u}{d \hat{h}} \theta r d r .
\end{array}
$$

Differentiating equation (7) and rearranging gives:

$$
\int_{0}^{\hat{r}}\left(\hat{D}_{\hat{h}}+\hat{D}_{u} \frac{d u}{d \hat{h}}\right) \theta r d r=-\int_{\hat{r}}^{\bar{r}} D_{u} \frac{d u}{d \hat{h}} \theta r d r-\hat{D} \theta \bar{r} \frac{d \bar{r}}{d \hat{h}}>0
$$

where the inequality follows from $D_{u}<0, d u / d \hat{h}<0, d \bar{r} / d \hat{h}<0$.

Since $\hat{r}<\bar{r}$ we have

$$
\begin{array}{r}
\int_{0}^{\hat{r}} r\left(\hat{D}_{\hat{h}}+\hat{D}_{u} \frac{d u}{d \hat{h}}\right) \theta r d r<-\int_{\hat{r}}^{\bar{r}} r D_{u} \frac{d u}{d \hat{h}} \theta r d r-\hat{r} \hat{D} \theta \bar{r} \frac{d \bar{r}}{d \hat{h}} \\
\Rightarrow \int_{0}^{\hat{r}} r\left(\hat{D}_{\hat{h}}+\hat{D}_{u} \frac{d u}{d \hat{h}}\right) \theta r d r+\int_{\hat{r}}^{\bar{r}} r D_{u} \frac{d u}{d \hat{h}} \theta r d r+\hat{r} \hat{D} \theta \bar{r} \frac{d \bar{r}}{d \hat{h}}<0,
\end{array}
$$

which shows that $d C / d \hat{h}<0$.

Since $S_{u}<0, d u / d \hat{h}<0$, the sign of $d H / d \hat{h}$ is ambiguous in general. At $k=1$, the 
FAR limit is not binding, which implies that $\hat{r}=0$ and therefore $d H /\left.d \hat{h}\right|_{k=1}<0$.

\section{References}

Bertaud, A. and Brueckner, J. K. (2005). Analyzing building-height restrictions: predicted impacts and welfare costs. Regional Science and Urban Economics, 35(2), 109 - 125.

Bessec, M. and Fouquau, J. (2008). The non-linear link between electricity consumption and temperature in Europe: A threshold panel approach. Energy Economics, 30(5), $2705-2721$.

Borck, R. and Pflüger, M. (2013). Green cities? urbanization, trade and the environment. Mimeo.

Borck, R. and Wrede, M. (2008). Commuting subsidies with two transport modes. Journal of Urban Economics, 63(3), 841 - 848.

Brueckner, J. K. (1987). The structure of urban equilibria: An integrated treatment of the Muth-Mills model. In E. S. Mills, editor, Handbook of Regional and Urban Economics Vol. II, chapter 20, pages 821-845. Elsevier, Amsterdam.

Dascher, K. (2013). City silhouette, world climate. MPRA Paper 48375, University Library of Munich, Germany.

Davis, M. A. and Ortalo-Magné, F. (2011). Household expenditures, wages, rents. Review of Economic Dynamics, 14(2), 248 - 261.

Gaigné, C., Riou, S., and Thisse, J.-F. (2012). Are compact cities environmentally friendly? Journal of Urban Economics, 72(23), 123-136.

Glaeser, E. L. (2009). Green cities, brown suburbs. City Journal, 19(1), 50-55.

Glaeser, E. L. and Kahn, M. E. (2010). The greenness of cities: Carbon dioxide emissions and urban development. Journal of Urban Economics, 67(3), 404-418.

infas Institut für angewandte Sozialwissenschaft and Deutsches Zentrum für Luft- und Raumfahrt Institut für Verkehrsforschung (2010). Mobilität in Deutschland 2008 Ergebnisbericht. Bonn and Berlin. 
Joshi, K. K. and Kono, T. (2009). Optimization of floor area ratio regulation in a growing city. Regional Science and Urban Economics, 39(4), 502 - 511.

Kono, T., Joshi, K. K., Kato, T., and Yokoi, T. (2012). Optimal regulation on building size and city boundary: An effective second-best remedy for traffic congestion externality. Regional Science and Urban Economics, 42(4), 619 - 630.

Krause, P., Goebel, J., Kroh, M., and Wagner, G. G. (2010). 20 Jahre Wiedervereinigung: Wie weit Ost- und Westdeutschland zusammengerückt sind. DIW Wochenbericht, $77(44), 2-12$.

Larson, W., Liu, F., and Yezer, A. (2012). Energy footprint of the city: Effects of urban land use and transportation policies. Journal of Urban Economics, 72(23), 147-159.

Legras, S. and Cavailhès, J. (2012). Urban form and sustainable development. CESAER Working Paper 2012/5, CESAER.

LeRoy, S. F. and Sonstelie, J. (1983). Paradise lost and regained: Transportation innovation, income, and residential location. Journal of Urban Economics, 13(1), 67-89.

Oke, T. R. (1981). Canyon geometry and the nocturnal urban heat island: Comparison of scale model and field observations. Journal of Climatology, 1(3), 237-254.

Rheinisch-Westfälisches Institut für Wirtschaftsforschung (RWI) and forsa Gesellschaft für Sozialforschung und statistische Analysen mbH (2013). Erhebung des Energieverbrauchs der privaten Haushalte für die Jahre 2009-2010. Project report, Essen.

Sasaki, K. (1990). Income class, modal choice, and urban spatial structure. Journal of Urban Economics, 27(3), 322-343.

Seto, K. C., Güneralp, B., and Hutyra, L. R. (2012). Global forecasts of urban expansion to 2030 and direct impacts on biodiversity and carbon pools. Proceedings of the National Academy of Sciences, 109(40), 16083-16088.

Small, K. A. (2012). Valuation of travel time. Economics of Transportation, 1(1-2), 2 14 .

Tscharaktschiew, S. and Hirte, G. (2010). The drawbacks and opportunities of carbon charges in metropolitan areas - a spatial general equilibrium approach. Ecological Economics, 70(2), 339-357. 